\title{
The role of expression and polymorphism of the BAG-1 gene in response to platinum-based chemotherapeutics in NSCLC
}

\author{
YA-DI WANG ${ }^{1}$, MIN-WEN HA ${ }^{2}$, JIAN CHENG ${ }^{2}$, WEN-LU ZHANG ${ }^{2}$, \\ XUE $\mathrm{CONG}^{2}$, CHUN-YAN TONG ${ }^{3}$ and $\mathrm{JING} \mathrm{SUN}^{4}$ \\ ${ }^{1}$ Liaoning Medical University, Jinzhou 121000; ${ }^{2}$ Department of Oncology, The First Affiliated Hospital of Liaoning \\ Medical University; ${ }^{3}$ Dalian Medical University, Dalian 116000, Liaoning; ${ }^{4}$ The Affiliated Hospital of Binzhou \\ Medical College, Binzhou 256200, Shandong, P.R. China
}

Received September 9, 2011; Accepted November 14, 2011

DOI: 10.3892/or.2011.1591

\begin{abstract}
We investigated the correlation between BAG-1 expression and sensitivity to platinum-based chemotherapeutics in patients with non-small cell lung cancer (NSCLC). mRNA and protein expression of BAG-1 in lung tissue of NSCLC postoperative patients (I-IIIA stage) or healthy subjects were detected using reverse transcription polymerase chain reaction (RT-PCR) and immunohistochemistry, respectively. Cox regression analysis was used to quantify the association of prognostic factors with survival in NSCLC patients. Venous blood samples from patients newly diagnosed with advanced NSCLC (IIIB-IV stage) were collected before chemotherapy to analyze allelic frequency and gene polymorphisms. Compared to healthy controls (11.67\%, 14 cases), levels of mRNA and protein of BAG-1 in lung tissues was significantly higher in NSCLC patients $(61.67 \%, 74$ cases $)\left(\chi^{2}=5.601, \mathrm{P}<0.05\right)$. Moreover, BAG-1 expression was identified as an independent prognostic factor for survival in NSCLC patients. As time to progression and survival rate was dramatically increased, patients with a positive expression of BAG-1 exhibited a prolonged survival period (TTP, 49.3 months; 5-year survival rat, 16.21\%) compared with those without BAG-1 expression $\left(\chi^{2}=7.243, \mathrm{P}<0.05\right)$. Two BAG-1 digestion patterns (CC and CT) were identified and confirmed. Patients (77.46\%) had a C/C genotype at BAG-1 codon 324 , while $22.54 \%$ had the $\mathrm{C} / \mathrm{T}$ genotype. The T/T genotype was not present in these patients. The progression risk of patients carrying the $\mathrm{C} / \mathrm{C}$ genotype at Bag- 1 codon 324 was 1.87 times higher than that of patients carrying the $\mathrm{C} / \mathrm{T}$ genotype $(\mathrm{P}<0.001)$. Follow-up examination showed that the chemotherapeutic sensitivity of patients carrying the $\mathrm{C} / \mathrm{C}$ genotype was 2.852 times higher than that
\end{abstract}

Correspondence to: Dr Min-Wen Ha, Department of Oncology, The First Affiliated Hospital of Liaoning Medical University, Jinzhou 121000, P.R. China

E-mail: yadi2006215@126.com

Key words: BAG-1, non-small cell lung cancer, platinum-based chemotherapeutics, sensitivity, genotype, RT-PCR of patients carrying the C/T genotype (95\% CI, 1.133-7.182; $\mathrm{P}=0.026)$. Significant differences were found in the median progression-free survival (PFS) and overall survival (OS) of these two cohorts of patients. Compared to patients carrying the $\mathrm{C} / \mathrm{T}$ genotype of BAG-1, patients carrying the $\mathrm{C} / \mathrm{C}$ genotype at Bag-1 codon 324 exhibited better responses to platinum-based chemotherapy. Hence, the expression of BAG-1 was closely associated with the sensitivity to platinum-based chemotherapeutics in NSCLC patients.

\section{Introduction}

Lung cancer is a leading cause of cancer-related deaths in both men and women worldwide (1). Approximately $80 \%$ of these patients represent non-small cell lung cancer (NSCLC). Without treatment, the median survival of patients with NSCLC is 4-5 months, with a survival rate at one year of $10 \%$ (2). Chemotherapy is recognized as efficient treatment for patients with advanced NSCLC since it reduces symptoms and improves the quality of life $(3,4)$. Importantly, standard regimens of platinum-based chemotherapy resulted in a median survival of $\sim 10$ months (5). However, low response rates to platinum-based chemotherapy in patients with advanced NSCLC were observed due to the resistance to platinum compounds (6).

BAG-1 is an anti-apoptotic protein which binds to a variety of cellular proteins and modulates their intracellular functions (7-9). Moreover, overexpression of BAG-1 has been found in many forms of cancers, including breast, lung, squamous cell carcinomas and glioblastoma (10). Enhanced expression of BAG-1 was also detected in tumor samples obtained from patients with NSCLC (11). However, the involvement of BAG-1 in the tumor development and chemotherapy in NSCLC patients has not been clarified.

Particular gene polymorphisms may modify the susceptibility to NSCLC development, which includes the $308 \mathrm{G} / \mathrm{A}$ and $238 \mathrm{G} / \mathrm{A}$ polymorphisms in the promoter region of TNF- $\alpha$, the cyclin D1 (CCND1) A870G gene polymorphism and the matrix metalloproteinase (MMP) 3 promoter polymorphism (12-14). DNA sequencing analysis exhibited that $\mathrm{C} / \mathrm{T}$ transition occurred in exon 7 of BAG-1 gene codon 324, leading to changes in the encoded amino acid from Thr to Ile (15). Such 
Table I. Relationship between BAG-1 expression and clinicopathological characteristics of NSCLC patients.

\begin{tabular}{|c|c|c|c|c|}
\hline & \multirow[b]{2}{*}{$\mathrm{n}$} & \multicolumn{2}{|c|}{ BAG-1 expression } & \multirow[b]{2}{*}{ P-value } \\
\hline & & Positive & Negative & \\
\hline \multicolumn{5}{|l|}{ Subjects } \\
\hline Healthy control & 120 & 14 & 106 & \multirow[t]{3}{*}{$<0.05$} \\
\hline NSCLC & 120 & 86 & 34 & \\
\hline Benign lung tumor & 10 & 1 & 9 & \\
\hline \multicolumn{5}{|l|}{ Gender } \\
\hline Male & 90 & 66 & 24 & \multirow[t]{2}{*}{$>0.05$} \\
\hline Female & 28 & 20 & 8 & \\
\hline \multicolumn{5}{|l|}{ Age (years) } \\
\hline$\leq 52$ & 56 & 42 & 14 & \multirow[t]{2}{*}{$>0.05$} \\
\hline$>52$ & 64 & 44 & 20 & \\
\hline \multicolumn{5}{|l|}{ Pathological types } \\
\hline Squamous carcinoma & 62 & 44 & 18 & \multirow[t]{2}{*}{$>0.05$} \\
\hline Adenocarcinoma & 58 & 42 & 16 & \\
\hline \multicolumn{5}{|l|}{ Differentiation stage } \\
\hline Moderate/high differentiation & 68 & 56 & 12 & \multirow[t]{2}{*}{$<0.05$} \\
\hline Poor differentiation & 52 & 30 & 22 & \\
\hline \multicolumn{5}{|l|}{ Clinical stage } \\
\hline $\mathrm{I}+\mathrm{II}$ & 90 & 66 & 24 & \multirow[t]{2}{*}{$>0.05$} \\
\hline IIIA & 30 & 20 & 10 & \\
\hline \multicolumn{5}{|l|}{ Node metastasis } \\
\hline With lymph node metastasis & 78 & 50 & 28 & \multirow[t]{2}{*}{$>0.05$} \\
\hline Without lymph node metastasis & 42 & 28 & 14 & \\
\hline
\end{tabular}

Data are presented as the number of cases. $\mathrm{P}<0.05$ (bold text) indicates statistically significant difference.

gene polymorphisms may affect the susceptibility to tumor development. Hence, characterization of a genetic profile unveils the critical role in contributing to the definition of a better chemotherapy treatment.

In the present study, elevated BAG-1 expression was found in the tumor tissues of patients with NSCLC. This study also advanced NSCLC patients by examining the blood of Bag-1 expression in various genotypes on the efficacy of chemotherapy regimens containing different platinum. The genotype at $\mathrm{C} / \mathrm{C}$ genotype at $\mathrm{Bag}-1$ condon 324 was closely correlated with the sensitivity to platinum-based chemotherapeutics in advanced NSCLC patients. These observations provide a theoretic basis for the design of individual chemotherapies for NSCLC patients.

\section{Materials and methods}

Patients. A total of 120 patients who underwent NSCLC surgery (I-IIIA stage) were selected from the First Affiliated Hospital of Liaoning Medical University between May 2004 and March 2006. Clinicopathological features of these patients are summarized in Table I. Samples used for immu- nohistochemistry and reverse transcription polymerase chain reaction (RT-PCR) were obtained from these patients. In China, NSCLC accounts for $80-85 \%$ of lung cancers and most patients $(>70 \%)$ at the time of diagnosis are at unresectable IIIB or IV stage. In order to analyze the allelic frequency and gene polymorphism of Bag-1 at codon 324, 142 patients with newly diagnosed advanced NSCLC (IIIB-IV stage) assessed via bronchofiberscope or exfoliative cytological were included (Table IV). Since small amounts of pathological tissues obtained by puncture were not enough for the follow-up study, venous blood samples were collected prior to chemotherapy. All patients with a Karnofsky performance status (KPS) score $\geq 70$ had solid tumors, which were confirmed by computed tomography (CT) or magnetic resonance imaging (MRI). Blood, liver and renal functions and electrocardiograms were within normal range. Informed consent was obtained from all participants who met eligibility criteria. The ethics committee at the First Affiliated Hospital of Liaoning Medical University approved this study.

Chemotherapy. Sixty-six cases were treated with an intraperitoneal (IP) injection of cisplatin (DDP) $\left(30 \mathrm{mg} / \mathrm{m}^{2}\right)$ for 
2-4 days and vinorelbine (NVB) $\left(25 \mathrm{mg} / \mathrm{m}^{2}\right)$ on Days 1 and 8. Seventy-six patients were treated with IP injections of DDP $\left(30 \mathrm{mg} / \mathrm{m}^{2}\right)$ for $2-4$ days and paclitaxel (TAX) $\left(175 \mathrm{mg} / \mathrm{m}^{2}\right)$ on Day 1 . The procedures were repeated every 3 or 5 weeks.

Immunohistochemistry and scoring methods. BAG-1 expression in tumor tissues from patients was detected using immunohistochemistry analysis. The $10 \%$ formalin-fixed and paraffin-embedded tissue sections were stained with anti-BAG-1 antibody at a dilution of 1:150 (Santa Cruz Biotechnology, Santa Cruz, CA). Immunohistochemical analysis was performed with a two-step immunohistochemistry detection kit (PV-6000-G) according to the manufacturer's instructions (Beijing Zhong Shan-Golden Bridge Biological Technology Co., Ltd., Beijing, China). PBS was used instead of BAG-1 primary antibody as negative control. Micrographs were analyzed by microscopy image technology. BAG-1 mainly distributed in nuclear, showing brown-yellow or dark brown vesicles. Five fields were randomly selected under microscope and the immunostaining was scored as previously described (6). The intensity of immunostaining was scored as: 0 , negative staining; 1 , light yellow; 2 , brown-yellow and 3 , dark brown. The percentage of the immuno-positive cells was assigned to one of five categories: 0 , negative staining; $1, \leq 10 \% ; 2,11-50 \% ; 3,51-75 \%$; and $4,>75.0 \%$. The weighted score for each tumor specimen was determined by multiplying the percentage score by the intensity score. The weighted score $\geq 3$ was recognized as positive.

$R T-P C R$. Total RNA was isolated using a kit (Tiangen Biotech Beijing Co., Ltd.) from $50 \mathrm{mg}$ tissue sample according to the manufacturer's instructions. cDNA was then transcribed with the application of Thermo M-MLV reverse transcriptase, Oligo (dT) and dNTP (Takara). Specific primers for BAG-1 or $\beta$-actin were designed using the Primer 5.0 software and were synthesized by Takara Biotechnology (Dalian, Co., Ltd.) as follows: Bag-1, forward: 5'-GTTG TCAGCACTTGGAATAC-3'; reverse: 5'-AGATGTTCTG CTCCACTGT-3'; $\beta$-actin, forward: 5'-AAGTACTCCGT GTGGATCGG-3'; reverse: 5'-ATGCTATCACCTCCCC TGTG-3'. PCR reaction was carried out in a final reaction volume of $25 \mu \mathrm{l}$ using the following conditions: a preheating cycle at $94^{\circ} \mathrm{C}$ for $5 \mathrm{~min}$, followed by 35 cycles at $94^{\circ} \mathrm{C}$ for $30 \mathrm{sec}, 53^{\circ} \mathrm{C}$ for $50 \mathrm{sec}$, and $72^{\circ} \mathrm{C}$ for $35 \mathrm{sec}$ and finally elongated at $72^{\circ} \mathrm{C}$ for $10 \mathrm{~min}$. The expected products were separated on a $1 \%$ agarose gel.

PCR-restriction fragment length polymorphism (PCR-RFLP) analysis. Prior to chemotherapy, 3-5 $\mathrm{ml}$ of venous blood was collected and DNA was extracted using AxyPrep Multisource Genomic DNA Minprep kit obtained from Axygen Biotechnology Ltd. (Hangzhou, Zhejiang, China). Specific primers for BAG-1 codon 324 (synthesized by Takara Biotechnology Dalian Co., Ltd.) were forward: 5'-CAGGTAGTGTAGGAGCGTGGTG-3'; and reverse: 5'-CACCCAGAGGTCCAAACAGC-3'. PCR reactions were carried out in a final reaction volume of $20 \mu \mathrm{l}$ using the following conditions: a preheating cycle at $95^{\circ} \mathrm{C}$ for $5 \mathrm{~min}$, followed by 35 cycles at $95^{\circ} \mathrm{C}$ for $30 \mathrm{sec}, 63^{\circ} \mathrm{C}$ for $45 \mathrm{sec}$, and $72^{\circ} \mathrm{C}$ for $45 \mathrm{sec}$ and finally elongated at $72^{\circ} \mathrm{C}$ for $10 \mathrm{~min}$.
A

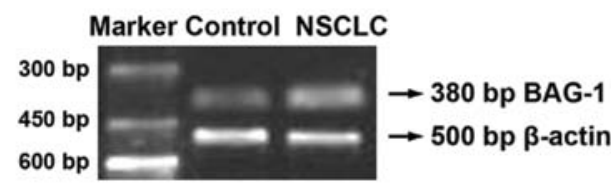

$\mathbf{B}$

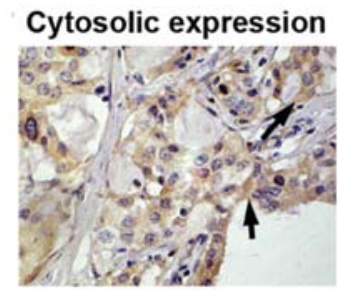

Squamous cell carcinoma negative control

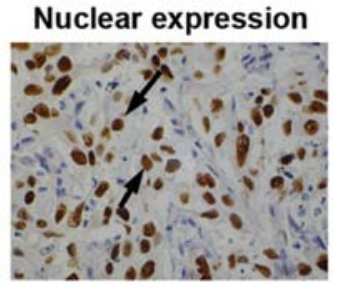

Adenocarcinoma negative control
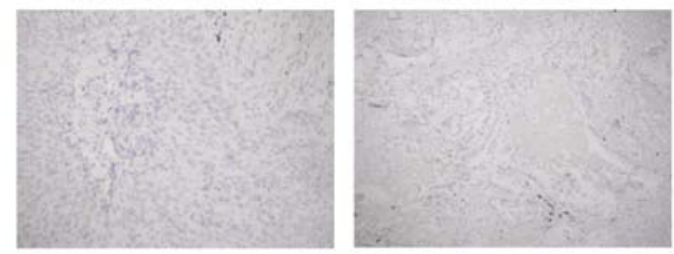

Figure 1. mRNA and protein expression of BAG-1 in lung tissues of NSCLC patients in I-IIIA stage. (A) Total RNA was isolated from lung tissues and RT-PCR was performed. Agarose gel eletrophoresis of PCR products were shown as indicated. Maker DL1000 was used to indicate PCR product lengths. Lung tissue samples obtained from healthy subjects were applied as control. (B) The $10 \%$ formalin-fixed and paraffin-embedded lung tissue sections were stained with anti-BAG-1 antibody. Immunoreactivity was visualized using an SP immunohistochemical staining kit according to the manufacturer's instructions. Immunohistochemical analysis showed cytosolic and nuclear expressions of BAG-1 in lung tissues of NSCLC patients Negative controls for specimens obtained from patients with squamous cell carcinoma and adenocarcinoma are presented.

The PCR products were digested using HpyCH4III restriction enzyme (New England BioLabs) and separated on a $3 \%$ agarose gel.

Therapeutic evaluation and survival analysis. Therapeutic effect was evaluated two or three weeks after chemotherapy according to the Response Evaluation Criteria In Solid Tumors (RECIST): complete response (CR), disappearance of all target lesions, confirmed at $\geq 4$ week; partial response (PR), $\geq 30 \%$ decrease from baseline, confirmed at 4 weeks; progressive disease (PD), $\geq 20 \%$ increase over the smallest sum observed, or appearance of new lesions; stable disease (SD), neither PR nor PD criteria were met. CR plus PR was recognized as a response, while SD+PD had no response. The overall survival of individual patients was defined from the day of surgery up to the last follow-up examination (July 31th, 2010). Median progression-free survival (PFS) and overall survival (OS) were plotted.

Statistical analyses. Statistical analyses were performed using SPSS 13.0 software. Data were presented as mean \pm standard deviation (SD). $\mathrm{P}<0.05$ was considered to be statistically significant. Comparisons between the two groups of subjects were performed using a $\chi^{2}$ test. Kaplan-Meier analysis was used to estimate survival. Differences between factors were evaluated using the log-rank test. Cox regression was used for determining prognostic factors. 
Table II. Survival analysis of NSCLC patients by Cox proportional hazards model.

\begin{tabular}{lcccc}
\hline & F & Hazard ratio & Wald & P-value \\
\hline Gender & 1 & 1.548 & 1.967 & 0.161 \\
Pathological types & 1 & 0.748 & 0.801 & 0.371 \\
Differentiation stage & 1 & 0.505 & 4.518 & $\mathbf{0 . 0 3 4}$ \\
Clinical stage & 1 & 2.014 & 4.798 & $\mathbf{0 . 0 2 8}$ \\
Node metastasis & 1 & 1.094 & 0.088 & 0.766 \\
BAG-1 positive & 1 & 0.513 & 7.613 & $\mathbf{0 . 0 0 6}$ \\
\hline
\end{tabular}

$\mathrm{P}<0.05$ (bold text) indicates statistically significant difference.

\section{Results}

Expression of BAG-1 in lung tissues of NSCLC patients. RT-PCR and immunohistochemistry were performed to examine the expression of BAG-1 in lung tissues of NSCLC patients and healthy subjects. As shown in Fig. 1A, enhanced BAG-1 mRNA level was detected in lung tissues of NSCLC patients, whereas a relatively low level of BAG-1 mRNA was found in lung tissues obtained from healthy controls. In addition, immunohistochemical analyses found that most of the BAG-1 protein was located in the cytoplasm, although nuclear staining of BAG-1 was also observed (Fig. 1B).

Relationship between BAG-1 expression and clinicopathological characteristics. We next evaluated the potential correlations between BAG-1 expression and clinicopathological characteristics of NSCLC patients. As shown in Table I, BAG-1 expression was closely related to differentiation stage, as elevated BAG-1 expression was found in patients with moderate/high differentiation as compared with poor differentiation $(\mathrm{P}=0.031)$. However, no statistically significant difference in BAG-1 expression was found in the various genders, ages, pathological types, clinical stages or node metastases $(\mathrm{P}>0.05$, Table I). Statistical analyses showed that $11.67 \%$ (14 cases) of healthy subjects and $61.67 \%$ (74 cases) of NSCLC patients expressed both mRNA and BAG-1 protein in the lung. BAG-1 expression was significantly higher in NSCLC patients than in healthy controls $\left(\chi^{2}=5.601, \mathrm{P}<0.05\right)$.

Survival analysis. Multivariate analyses (Cox regression model) were used to examine the correlation between prognostic factors and survival in NSCLC patients. As shown in Table II, differentiation stage, clinical stage as well as BAG-1 expression were identified as the independent prognostic factors for survival in patients with NSCLC $(\mathrm{P}<0.05)$. Overall survival (OS) was counted from the day of surgery to the last follow-up examination and was longer with BAG-1 positive as compared with BAG-1 negative (log-rank test, $\mathrm{P}=0.045$ ) (Fig. 2A). Life-table analysis showed that the time to progression (TTP) of NSCLC patients with BAG-1 negative expression ( 46 cases) was 37.5 months and the 5-year survival rate was $8.69 \%$. However, both TTP and the survival rate of NSCLC patients with BAG-1 positive expression (74 cases) were dramatically increased (TTP, 49.3 months; 5 -year survival rate, $16.21 \%)\left(\chi^{2}=7.243, \mathrm{P}=0.007\right)$ (Fig. 2B). These results suggested that BAG-1 expression was positively associated with prolonged survival of patients with NSCLC.

Evaluation of genotype frequencies and Hardy-Weinberg equilibrium testing. A total of 142 patients with newly diagnosed advanced NSCLC were included for determination of genotype frequencies. Venous blood samples were collected and BAG-1 DNA (861 bp in length) was amplified using PCR (Fig. 3A). Two BAG-1 digestion patterns were identified by digestion: 72, 197, 282 and 310 bp fragments as wild homozygous CC genotype; 72, 197, 282, 310 and 592 bp fragments as heterozygous CT genotype (Fig. 3B). The PCR products were confirmed by DNA sequencing (Fig. 3C and D). In addition,
A

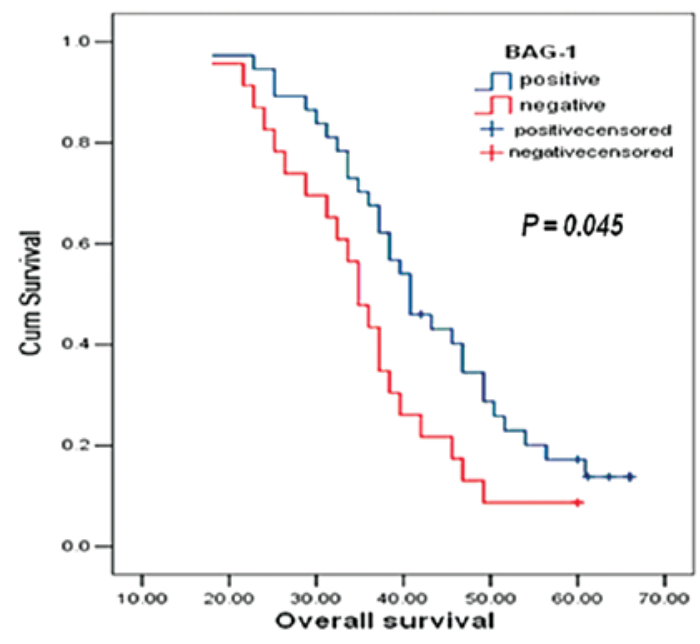

B

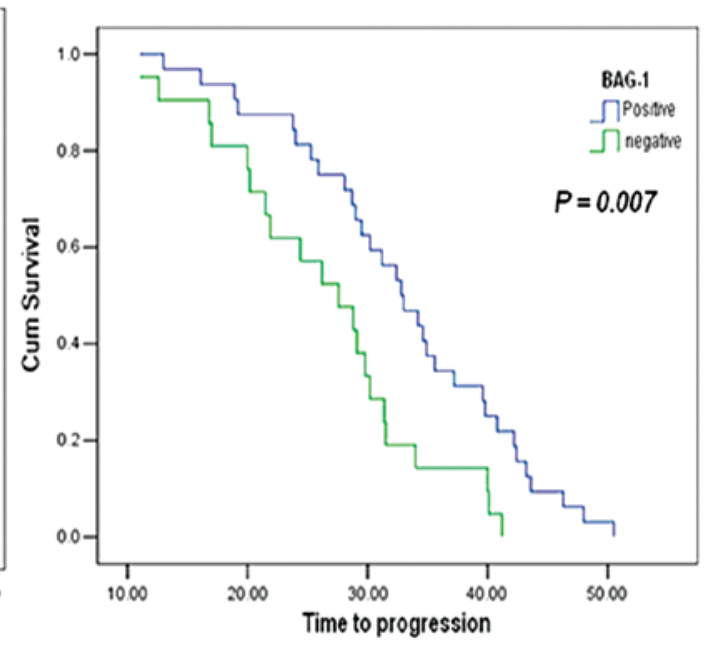

Figure 2. Survival curves of patients. (A) The overall survival of NSCLC patients with BAG-positive or -negative expression $\left(\chi^{2}=4.032\right.$, $\left.P=0.045\right)$. (B) The time to progression of NSCLC patients with BAG-positive or -negative expression $\left(\chi^{2}=7.243, \mathrm{P}=0.007\right)$. 
A

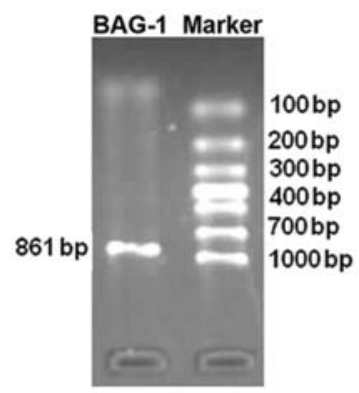

B

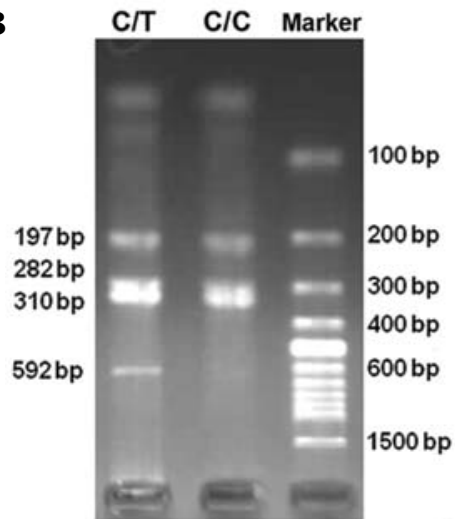

C

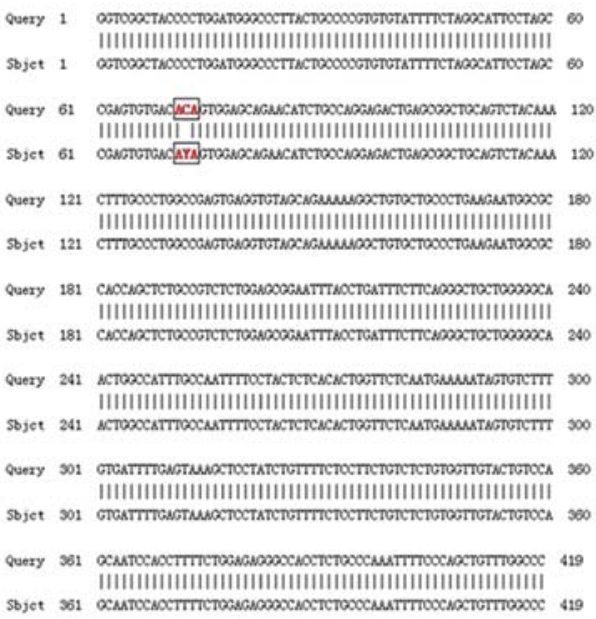

D

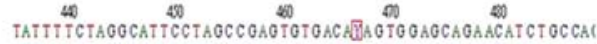

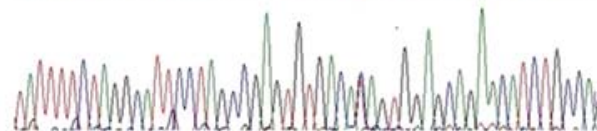

Figure 3. Two genotypes were identified at BAG-1 condon 324 in 142 patients with newly diagnosed advanced NSCLC (IIIB-IV stage). (A) PCR amplification product of BAG-1 DNA (861 bp). Marker, DL1000 DNA marker. (B) PCR products were digested by HpyCH4III restriction enzyme and separated on a 3\% agarose gel. Marker, DNA marker 100 bp. (C) DNA sequencing of the PCR products. (D) Wave curves of DNA sequencing. Note that there was one single nucleotide mutation in the boxed site. Y stands for the $\mathrm{C}, \mathrm{T}$ bases.

Table III. Correlation between gene polymorphism and the effect of chemotherapy.

\begin{tabular}{lcccccr}
\hline & \multicolumn{2}{c}{ The effect of chemotherapy } & & & & \\
nenotype & SD+PD cases (\%) & CR+PR cases (\%) & $\chi^{2}$ & P-value & OR & $95 \%$ CI \\
\hline C/C & 64 & 39 & 4.254 & 0.039 & 2.852 & $1.133-7.182$ \\
C/T & 32 & 7 & & & & \\
\hline
\end{tabular}

$\mathrm{SD}$, stable disease; $\mathrm{PD}$, progressive disease; $\mathrm{CR}$, complete response; $\mathrm{PR}$, partial response.

110 out of 142 cases $(77.46 \%)$ had the C/C genotype at BAG-1 nucleotide codon 324 , while 32 out of 142 cases $(22.54 \%)$ had the $\mathrm{C} / \mathrm{T}$ genotype at codon 324 . The T/T genotype was not found in these patients. Each genotype observed in the NSCLC patients were not significantly different for the values expected at BAG-1 codon 324 according to Hardy-Weinberg equilibrium $\left(\chi^{2}=3.598, \mathrm{P}=0.057\right)$. This indicates that two types of polymorphisms come from the mendelian population, which is in accordance with genetic equilibrium.

The correlation between gene polymorphism and the sensitivity to chemotherapy. The association between gene polymorphism $(\mathrm{C} / \mathrm{C}, \mathrm{C} / \mathrm{T})$ and the effect of chemotherapy were tested. Therapeutic effect was evaluated two or three weeks following chemotherapy according to the RECIST as described in Patients and methods. Note that the Bag- 1 polymorphisms might influence clinical outcomes to chemotherapy as NSCLC patients carrying the C/C genotype exhibited better responses to chemotherapy (Table III). However, other factors, including gender, age, smoking, pathological types, differentiation stage, clinical stage, KPS score and chemotherapy regimens, were not significantly correlated with chemotherapy sensitivity ( $P>0.05$, Table IV). These results demonstrated that the sensitivity to chemotherapy in NSCLC patients were associated with Bag-1 polymorphisms at codon 324 .

Correlation between gene polymorphism and survival of NSCLC patients. Kaplan Meier analyses showed that statistically significant differences were observed in both progression free survival (PFS) and overall survival (OS) of NSCLC patients carrying the $\mathrm{C} / \mathrm{C}$ genotype or $\mathrm{C} / \mathrm{T}$ genotype 
Table IV. Association between clinicopathological factors and chemotherapeutic efficacy in NSCLC patients.

\begin{tabular}{|c|c|c|c|c|}
\hline \multirow[b]{2}{*}{ Variables } & \multicolumn{2}{|c|}{$\begin{array}{l}\text { The effect of } \\
\text { chemotherapy }\end{array}$} & \multirow[b]{2}{*}{$\chi^{2}$} & \multirow[b]{2}{*}{ P-value } \\
\hline & $\begin{array}{l}\mathrm{SD}+\mathrm{PD} \\
\text { cases }\end{array}$ & $\begin{array}{c}\mathrm{CR}+\mathrm{PR} \\
\text { cases }\end{array}$ & & \\
\hline \multicolumn{5}{|l|}{ Gender } \\
\hline Male & 61 & 28 & 0.095 & 0.758 \\
\hline Female & 35 & 18 & & \\
\hline \multicolumn{5}{|l|}{ Age (years) } \\
\hline$\geq 52$ & 56 & 22 & 0.375 & 0.540 \\
\hline$<52$ & 40 & 24 & & \\
\hline \multicolumn{5}{|l|}{ Smoking } \\
\hline Yes & 59 & 20 & 3.377 & 0.066 \\
\hline No & 37 & 26 & & \\
\hline \multicolumn{5}{|l|}{ Pathological type } \\
\hline Squamous carcinoma & 52 & 30 & & \\
\hline Adenocarcinoma & 44 & 16 & 1.136 & 2.286 \\
\hline \multicolumn{5}{|l|}{ Grade } \\
\hline High & 22 & 16 & 3.527 & 0.06 \\
\hline Intermidiate & 38 & 20 & & \\
\hline Low & 36 & 10 & & \\
\hline High and intermediate & 60 & 36 & & \\
\hline \multicolumn{5}{|l|}{ Clinical stage } \\
\hline IIIB & 61 & 35 & 1.699 & 0.192 \\
\hline IV & 35 & 11 & & \\
\hline \multicolumn{5}{|l|}{ PS } \\
\hline 70 & 30 & 12 & 1.129 & 0.569 \\
\hline 80 & 35 & 15 & & \\
\hline 90 & 31 & 18 & & \\
\hline \multicolumn{5}{|l|}{ Chemotherapy regimens } \\
\hline $\mathrm{DDP}+\mathrm{NVB}$ & 49 & 17 & & \\
\hline DDP+TAX & 47 & 29 & 1.946 & 0.163 \\
\hline
\end{tabular}

$\mathrm{SD}$, stable disease; $\mathrm{PD}$, progressive disease; $\mathrm{CR}$, complete response; $\mathrm{PR}$, partial response.

(PFS, P=0.002; OS, $\mathrm{P}=0.013$ ) (Fig. 4). NSCLC patients carrying the $\mathrm{C} / \mathrm{C}$ genotype exhibited prolonged PFS and OS as compared with those carrying the $\mathrm{C} / \mathrm{T}$ genotype at Bag- 1 codon 324. Cox proportional hazards analyses further revealed that, besides gene polymorphisms, the PFS was also associated with the clinical stage and differentiation stage of patients with advanced NSCLC (Table V). Note that the progression risks of patients carrying the $\mathrm{C} / \mathrm{C}$ genotype at Bag-1 codon 324 were 1.87 times higher than in patients carrying the $\mathrm{C} / \mathrm{T}$ genotype (Table $\mathrm{V}$ ). Hence, advanced clinical stage, poor differentiation, C/T genotype at Bag-1 codon 324 could be key factors contributing to the development of NSCLC. Moreover, we found that gender, age, KPS score were not correlated with PFS (gender, $\mathrm{P}=0.831$; age, $\mathrm{P}=0.585$; KPS score, $\mathrm{P}=0.155$ ).

\section{Discussion}

Expression of a variety of anti-apoptotic genes are involved in the development of NSCLC. Elevated Bcl-2 levels were linked to increased disease-free and overall survival (16), while decreasing Bcl-2 expression was related to metastatic NSCLC (17). Altered expression of the p53 gene was correlated with poor survival in NSCLC patients (18). The Bcl-2-binding protein BAG-1 (19), has been recognized as a multifunctional regulator of cell growth, survival and death $(8,9)$. Overexpression of BAG-1 inhibits caspase activation induced by chemotherapeutic agents, radiation and growth factor deprivation, and therefore suppresses apoptotic cell death $(20,21)$. However, the mechanism by which BAG-1 mediates cell survival is poorly understood. Importantly, overexpression of BAG-1 is linked to various human cancers, and may serve as an independent prognostic factor in the management of certain cancers (10). For example, BAG-1 isoforms are potential molecular markers for the pathogenesis of breast cancer $(22,23)$. However, the correlation between BAG-1 expression and NSCLC occurrence has not been illustrated.

In the present study, we found that $11.67 \%$ (14 cases) of healthy subjects and $61.67 \%$ (74 cases) of NSCLC patients expressed both mRNA and protein of lung BAG-1. These observations were consistent with a previous report which showed overexpression of BAG-1 in 73\% NSCLC patients $(n=85)$ (11). In addition, immunostaining showed that BAG-1 protein was mostly located in the cytoplasm, although the nucleus was also observed (Fig. 1B). Studies have suggested that expression of BAG-1 in the cytoplasm might be related to a reduced risk of death in patients with NSCLC (11).

BAG-1 expression was found to be related to the differentiation of NSCLC, but not other clinicopathological characteristics, including gender, age, pathological types, clinical stage or node metastasis (Table I), suggesting BAG-1 may be involved in the progress of NSCLC and contribute to disease development. Cox multivariate analysis revealed that tumor differentiation, clinical stage as well as BAG-1 expression were independent prognostic factors for survival in patients with NSCLC (Table II). Compared with patients without BAG-1, TTP and survival rate of NSCLC patients with BAG-1 positive expression were significantly increased. This, together with another report (11), demonstrated that BAG-1 expression was sensitive to chemotherapy and could serve as an independent prognostic factor in NSCLC. However, our results demonstrating a correlation between BAG-1 expression and lung cancer patient survival was contrary to a recent study, which showed that TNM stage I lung cancer patients with BAG-1 low-expression had better survival compared to patients with high expression of BAG-1 (24). This discrepancy may be due to the different types of lung cancer studied.

Theoretically, patients with high expression of the anti-apoptosis protein BAG-1 should have poor prognosis. However, in this present study, we found that BAG-1 expression was positively associated with prolonged survival of patients with NSCLC. It is possible since the anti-apoptotic activity of tumor cells may also benefit patients with NSCLC. 
A

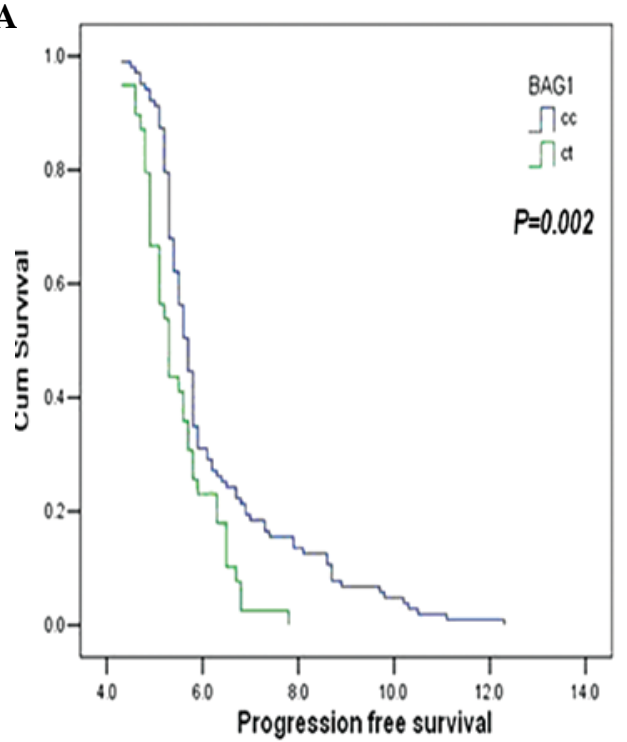

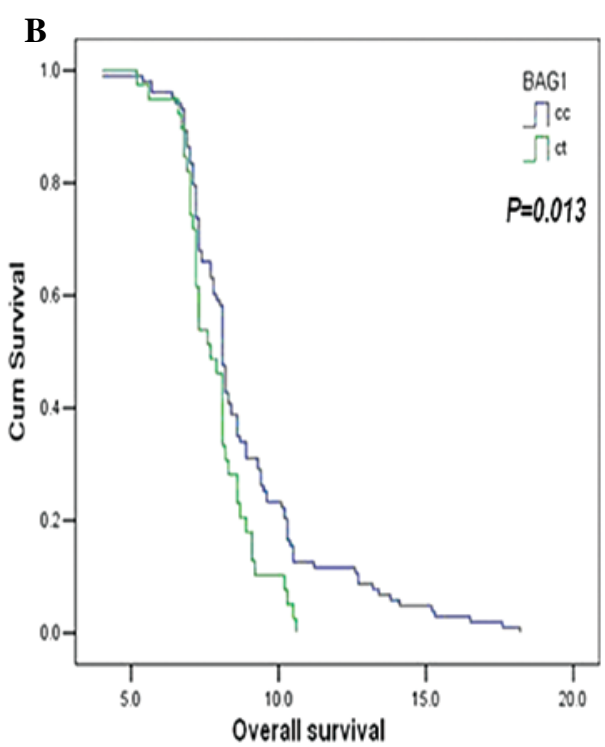

Figure 4. Correlation between gene polymorphism and patient survival. (A) Progression free survival of NSCLC patients carrying C/C or C/T at Bag-1 codon 324. (B) Overall survival of NSCLC patients carrying C/C or C/T at Bag-1 codon 324.

Table V. Correlation between progression-free survival and clinical stage, differentiation and gene polymorphism.

\begin{tabular}{lccrrrrr}
\hline & Regression coefficient b & Standard error b & Wald & V & P-value & OR & $95 \%$ CI \\
\hline Clinical stage $^{\mathrm{a}}$ & 0.658 & 0.194 & 11.472 & 1 & 0.001 & 1.930 & $1.319-2.825$ \\
Differentiation stage $^{\mathrm{b}}$ & 0.353 & 0.117 & 9.120 & 1 & 0.003 & 1.423 & $1.132-1.789$ \\
C324T $^{c}$ & 0.629 & 0.199 & 10.045 & 1 & 0.002 & 1.870 & $1.272-2.770$ \\
\hline
\end{tabular}

${ }^{a}$ III stage v.s. IV stage; ${ }^{b}$ moderate/high differentiation v.s. poor differentiation; ${ }^{c} \mathrm{C} / \mathrm{C}$ v.s. $\mathrm{C} / \mathrm{T}$. $\mathrm{P}<0.05$ indicates statistically significant difference

Tormanen et al analyzed 75 cases of NSCLC and revealed that enhanced apoptosis showed a 1.9 -fold risk for a shortened survival in NSCLC patients (25). Nevertheless, the involved mechanism needs to be further clarified.

In addition to the anti-apoptotic effect of BAG-1 during cancer development, BAG-1 may also contribute to drug resistance of chemotherapy. In HeLa cells, down-regulation of BAG-1 conferred resistance to anti-cancer drugs, including actinomycin D, camptothecin, paclitaxel, staurosporine, thapsigargin and etoposide (26). Liu et al (24) reported that knock down of BAG-1 by RNA interference (RNAi) sensitized lung cancer cell lines (A549 and L9981) to cisplatin-induced apoptosis. In the present study, we found that BAG-1 expression was closely associated with the sensitivity to platinum-based chemotherapeutics in NSCLC patients, suggesting BAG-1 may be a biomarker for evaluating sensitivity to chemotherapy.

PCR-RFLP technique was applied to screen for DNA polymorphisms of BAG-1 in codon 324. C/C and C/T genotypes were detected in a total of 142 patients with newly diagnosed advanced NSCLC. NSCLC patients carrying the C/C genotype exhibited better responses to chemotherapy, with prolonged PFS and OS, as compared with those carrying the C/T genotype (Table III, Fig. 4). A previous study showed that BAG-1 is a novel regulator of nuclear factor- $\kappa \mathrm{B}(\mathrm{NF}-\kappa \mathrm{B})$ as knock down of BAG-1 inhibited NF- $\mathrm{B}$ activity (27). Therefore, we reasoned that the $\mathrm{C} / \mathrm{T}$ transition at the BAG-1 codon 324 induced changes in encoded amino acid from Thr to Ile that contributed to alterations in protein expression and inhibition of apoptotic pathways triggered by chemotherapeutic drugs. In addition, the T/T genotype was not observed in this study, which might be due to the low incidence of two allele mutations (28). However, we cannot rule out the possibility that this may be due to the small number of patients in our study. Therefore, BAG-1 codon 324 gene polymorphism serves as a biomarker for predicting the sensitivity of chemotherapy, and may provide a theoretical basis for individual treatment of patients with advanced NSCLC.

In summary, our results indicate that BAG-1 is overexpressed in patients with NSCLC, which is associated with sensitivity to platinum-based chemotherapeutics. These results imply that BAG-1 may be a novel biomarker for predicting the sensitivity to chemotherapy and provide evidence for the application of individualized therapy in NSCLC. Future studies are needed to explore the mechanisms by which BAG-1 is involved in NSCLC progression.

\section{Acknowledgements}

This study was supported by the Scientific Research Fund of Liaoning Provincial Education Department (Grant no. 
L2010286). We thank Medjaden Bioscience Limited for assisting in the preparation of this manuscript.

\section{References}

1. Jemal A, Siegel R, Xu J and Ward E: Cancer statistics, 2010. CA Cancer J Clin 60: 277-300, 2010.

2. Rapp E, Pater JL, Willan A, et al: Chemotherapy can prolong survival in patients with advanced non-small cell lung cancerreport of a Canadian multicenter randomized trial. J Clin Oncol 6: 633-641, 1988.

3. Grilli R, Oxman AD and Julian JA: Chemotherapy for advanced non-small cell lung cancer: how much benefit is enough? J Clin Oncol 11: 1866-1872, 1993.

4. Cullen MH, Billingham LJ, Woodroffe CM, et al: Mitomycin, ifosfamide, and cisplatin in unresectable non-small cell lung cancer: effects on survival and quality of life. J Clin Oncol 17: 3188-3194, 1999.

5. Schiller JH, Harrington D, Belani CP, et al: Comparison of four chemotherapy regimens for advanced non-small cell lung cancer. N Engl J Med 346: 92-98, 2002.

6. Belani CP and Langer C: First-line chemotherapy for NSCLC: an overview of relevant trials. Lung Cancer 38 (Suppl 4): 13-19, 2002.

7. Tang SC: BAG-1, an anti-apoptotic tumour marker. IUBMB Life 53: 99-105, 2002.

8. Townsend PA, Cutress RI, Sharp A, Brimmell M and Packham G: BAG-1: a multifunctional regulator of cell growth and survival. Biochim Biophys Acta 1603: 83-98, 2003.

9. Liman J, Faida L, Dohm CP, Reed JC, Bahr M and Kermer P: Subcellular distribution affects BAG1 function. Brain Res 1198: 21-26, 2008.

10. Cutress RI, Townsend PA, Brimmell M, Bateman AC, Hague A and Packham G: BAG-1 expression and function in human cancer. Br J Cancer 87: 834-839, 2002.

11. Rorke S, Murphy S, Khalifa M, Chernenko G and Tang SC: Prognostic significance of BAG-1 expression in non-small cell lung cancer. Int J Cancer 95: 317-322, 2001.

12. Gautschi O, Hugli B, Ziegler A, et al: Cyclin D1 (CCND1) A870G gene polymorphism modulates smoking-induced lung cancer risk and response to platinum-based chemotherapy in non-small cell lung cancer (NSCLC) patients. Lung Cancer 51: 303-311, 2006

13. Shih CM, Lee YL, Chiou HL, et al: Association of TNF-alpha polymorphism with susceptibility to and severity of non-small cell lung cancer. Lung Cancer 52: 15-20, 2006.

14. Fang S, Jin X, Wang R, et al: Polymorphisms in the MMP1 and MMP3 promoter and non-small cell lung carcinoma in North China. Carcinogenesis 26: 481-486, 2005.
15. Humphray SJ, Oliver K, Hunt AR, et al: DNA sequence and analysis of human chromosome 9. Nature 429: 369-374, 2004.

16. Silvestrini R, Costa A, Lequaglie $\mathrm{C}$, et al: $\mathrm{Bcl}-2$ protein and prognosis in patients with potentially curable non-small cell lung cancer. Virchows Arch 432: 441-444, 1998.

17. Dosaka-Akita H, Katabami M, Hommura H, Fujioka Y, Katoh $\mathrm{H}$ and Kawakami Y: Bcl-2 expression in non-small cell lung cancers: higher frequency of expression in squamous cell carcinomas with earlier pT status. Oncology 56: 259-264, 1999.

18. Mitsudomi T, Hamajima N, Ogawa $M$ and Takahashi T: Prognostic significance of p53 alterations in patients with non-small cell lung cancer: a meta-analysis. Clin Cancer Res 6: 4055-4063, 2000.

19. Takayama S, Sato T, Krajewski S, et al: Cloning and functional analysis of BAG-1: a novel Bcl-2-binding protein with anti-cell death activity. Cell 80: 279-284, 1995.

20. Takayama S and Reed JC: Molecular chaperone targeting and regulation by BAG family proteins. Nat Cell Biol 3: E237-E241, 2001.

21. Hohfeld J: Regulation of the heat shock conjugate Hsc70 in the mammalian cell: the characterization of the anti-apoptotic protein BAG-1 provides novel insights. Biol Chem 379: 269-274, 1998.

22. Millar EK, Anderson LR, McNeil CM, et al: BAG-1 predicts patient outcome and tamoxifen responsiveness in ER-positive invasive ductal carcinoma of the breast. Br J Cancer 100: 123-133, 2009.

23. Nadler Y, Camp RL, Giltnane JM, et al: Expression patterns and prognostic value of Bag-1 and Bcl-2 in breast cancer. Breast Cancer Res 10: R35, 2008.

24. Liu H, Bai Y, Liu B, et al: The expression of BAG-1 and its clinical significance in human lung cancer. Zhongguo Fei Ai Za Zhi 11: 489-494, 2008 (In Chinese).

25. Tormanen U, Eerola AK, Rainio P, et al: Enhanced apoptosis predicts shortened survival in non-small cell lung carcinoma. Cancer Res 55: 5595-5602, 1995.

26. Takahashi N, Yanagihara M, Ogawa Y, Yamanoha B and Andoh T: Down-regulation of Bcl-2-interacting protein BAG-1 confers resistance to anti-cancer drugs. Biochem Biophys Res Commun 301: 798-803, 2003

27. Clemo NK, Collard TJ, Southern SL, et al: BAG-1 is up-regulated in colorectal tumour progression and promotes colorectal tumour cell survival through increased NF-kappaB activity. Carcinogenesis 29: 849-857, 2008.

28. Li J, Wang B and Li SN: Advances in the research of single nucleotide polymorphism. J Yunan Normal University (Natural Sciences Edition) 27: 40-44, 2007. 